\title{
Automatic Water Management System
}

\author{
Santosh Anand ${ }^{1}$, Adithya.S.Nath ${ }^{2}$, Aparna.P.Jayan ${ }^{3}$, Brunda.I.B ${ }^{4}$, Vidyashree.C ${ }^{5}$ \\ santoshanand.jha@gmail.com \\ Department of Computer Science \\ Amrita School of Arts and Sciences, Mysuru \\ Amrita Vishwa Vidyapeetham, India
}

\begin{abstract}
The developing populaces, and expanded requests from farming and industry, analysts demonstrated that this emergency is just prone to exacerbate. Presently the conserve of water has surpassed in metros and in countries. This is because of increase in populace and misuse of water. There is a need of water monitoring and control system in each and every sectors, starting from home to all kind of the offices. There are many existing work to eliminate the wastage of water such as automatic public tap control. This work, Automatic Water Management System (AWMS) is to observe and manage the wastage of water due to various reasons like tap leakage, pipe leakage and water tank overflow. It can deployed in each and every building which send the water level information to the owner of particular building. AWMS is designed and developed with efficient sensors, which can control wastage of water in less time.
\end{abstract}

Keywords: Arduino Microcontroller, Water Level Sensor, Wi-Fi Module , IoT

\section{Introduction}

In 2015,NASA's satellite information uncovered that 21 of the world's 37 huge springs are seriously waterpushed. The essential and most important thing in the world is WATER. Almost the earth's surface is covered with $70 \%$ of water, where about $2 \%$ of the planet's water is fresh. So water conservation is the critical issues in the current scenario of any countries. According to the survey, its observed that wastage of water is more compare than utilization since unfit and indigent water allocation and shortfall of consolidated water management systems. The current project helps to automate the system. Embedded systems are presently involved a lively role in engineering design procedure for systematized study and successful operation. Since time convolution in electronic outlook embedded systems have become a extensive part of our daily life. So there is a need of system which can properly control and monitor the water level, water leakage and control.

This prototype is designed with the help of embedded systems which can compute the level of water of storage tank and expose in LCD. It not only present the required information about the status of the water tank but also helps and diminish the and power required in this complete process.

Here the system is build-in with different efficient sensors which is integrated through the microcontroller and programmed with embedded C. Basically sensors are used in many fields and there are different and specific sensors to sense the data and to produce the desired output.

"Automatic Water Management system", it portrays in a way where the water can be monitored and also controlled in an efficient manner and also reduce the manpower. The water is mainly wasted in houses by water tank overflow, tap leakage and by pipe leakage.One main reason for these issues is the irresponsibility of the owner,and due to their busy life.This system is not only applicable in home automation rather, it can be implemented in Agriculture Fields, Industries, Factories, Poultry Farms, Public places or government sector for efficient use of water.

\section{Literature Survey}

Vinod Bharat., et al [1] An smart water management system used in cities. Here, the condition is about the local area protect or Wi-Fi protect which is connected to the microcontroller for the command to ON/OFF the motor consequently. Using internet the water distribution schedule is send to the people's mobile phone in cities. It creates an application to send the details to the water and also the operator can send any complaints if occurred. 
Yogita Patil ., et al [2] the prime component is Atmega 128A microcontroller. The author describes this system is mainly implemented to distribute ideal water circulation and in addition decrease manpower engaged within this. Initially, the current status of the tank is displayed on the LCD. If it indicates low then the pump is at ON mode and if at high the pump is OFF automatically. It is mainly used in Residential colonies, and also in chemical industries.

Ayisha Sayed., et al [3] this paper describes the dispersal and control system which is mainly used in flats and apartments. Water when contributed from the overhead tanks to individual flats, the tanks will be examined for its level using level sensors and a threshold will be set for individual users as stated to number of flats, because of this the user will be apprised with the limit of water to be used. The amount of water flow in the pipeline will be controlled according to the user's request.

S. Nalini Durga., et al [4] The process of water distribution is like if power available, system will check for the water level in the tank. If the power is not available, the same is intimated to the user using SMS, so that he can make essential arrangement for the water. Once the water level position to MAX level of the water tank then the motor will triggers to OFF as a result. Author describes using this system the Indication of Water levels in the Tank, Indication of Motor Running shall all be noticed.

Chanda Rajurkar., et al [5] According to this water use, information would be sent to cloud utilizing the IOT space. This cloud information would be sent to the concerned inhabitant's individual's mobile application. The cluster of data is by using IOT and the return of getting information from cloud to mobile application which can be utilized by the client or the head of corporation for review and controlling the inventory of water.

BezaNegashGetu., et al [6] the siphoning of water is through stream which acts as a switch to pump naturally. It gets on and begins filling the tank when the water level is vacant or level ONE and quit filling the tank when water level arrives at most extreme level NINE. The proposed framework abolishes manual checking and controlling for home, rural or modern clients.

Takshan Shetty., et al [7] The proposed system uses assured sensors to sense various stages of the storage. .LCD modules are very consistently used in most embedded projects, the cause is cheap price, availability and programmer friendly. Arduino UNO microcontroller utilized for building computerized gadgets and interactive items that can detect and control objects in the physical and advanced world. Where at each stages the position of the water level will be displayed in the LCD mentioned as $20 \%, 40 \%, 60 \%, 80 \%$ and at the top or $100 \%$ of the tank level.

F.Ntambi ,et al[8] This paper is used to perceive water leakages due to burst pipes. The data is sent remotely to the director where a graphical UI speaks to the information got and alerts the overseer of any abnormalities identified. All remote sensor hubs speak with one another remotely, and send data to a portal associated with a PC which has the GUI. All handling and calculation is done on the GUI.

Gowthamy J, et al [9] The author present the hypothesis on continuous observing of water quality and amount utilizing IoT. A Wi-Fi module is associated with the Arduino gadget which help to evacuate the information to the cloud over web. The water flow sensor measure the amount of water move through the funnel in a given time, this information will be sent to cloud for capacity and analysis purposes.

Gaurav Gosavi,et al[10] The move of water through the residential pipeline can be watched, estimated and visualized from anyplace on the planet utilizing web through PC or Smartphone and with the assistance of transistor and relay we can turn on turn off it at whatever point required.

Mr. Kuldip Singh et al[11] The programmed water supply framework depends on the Real time controlling framework. Through the sub-control room, the information is send at what time which zone water supply is going on. The system is mainly constituted with controlling device and communication device. The controlling gadget is introduce on valve side and when the valve will be open or close the data is update in Sub-Control room through specialized gadget.

\section{Proposed System}

\subsection{System Overview}


Automatic water control system senses the water movement and afterward demonstrates the water level inside the container and passes information to the owner through pop up message, which is shown in below figurel. The device will have water level sensor merged in the container, and by using IR sensor it helps to control the flowing of water from the tap. AWMS helps to detect the leakage in pipe with the $120 \mathrm{~dB}$ water leak alarm and make the continuous water flow from the tap in the case of less, medium and high level of water present in the water tank. Water leak alarm will send the signal to smart phone through the pop up message saying that water leakage in the pipe. So users can take the control decisions.

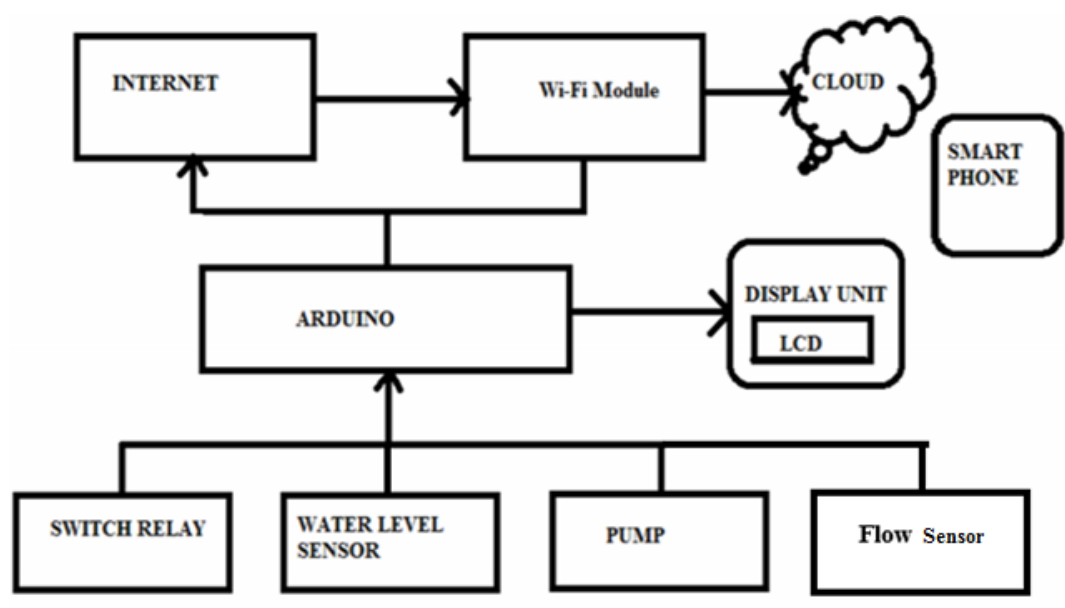

Fig 1: System Architecture

Arduino UNO:It is a Microcontroller board, which is having 14 digital pins for getting inputs and outputs, it is used in proposed system model and shown in figure2. All the hardware such as LCD, Wi-Fi module, Water Level Sensor, Switch relay etc are connected to the Arduino by Jumperd wires and for the further programing a USB connection is made from Arduino to the PC.

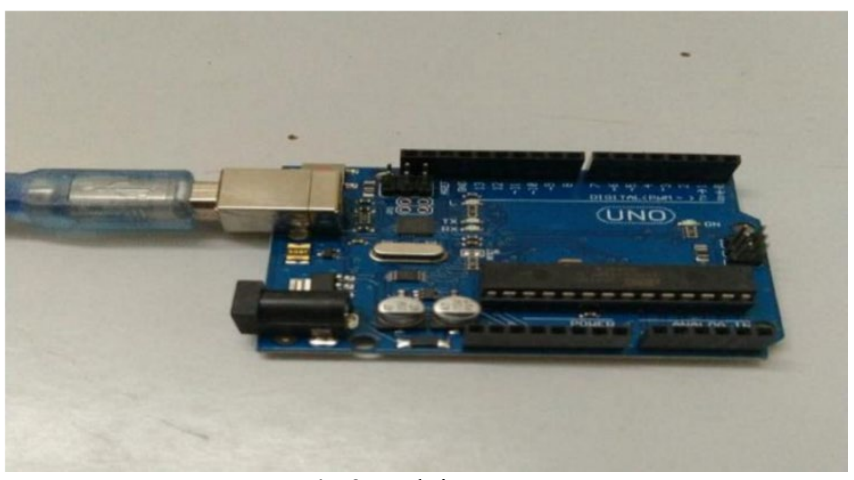

Fig 2:Arduino UNO

Water Level Sensor:It is a level detecting sensor used to sense the liquid level in a tank or container, shown in below figure 3 . The water in a tank is sensed and rated according to the inputs given in the program. The connection of water level sensor is generated from the Arduino board.

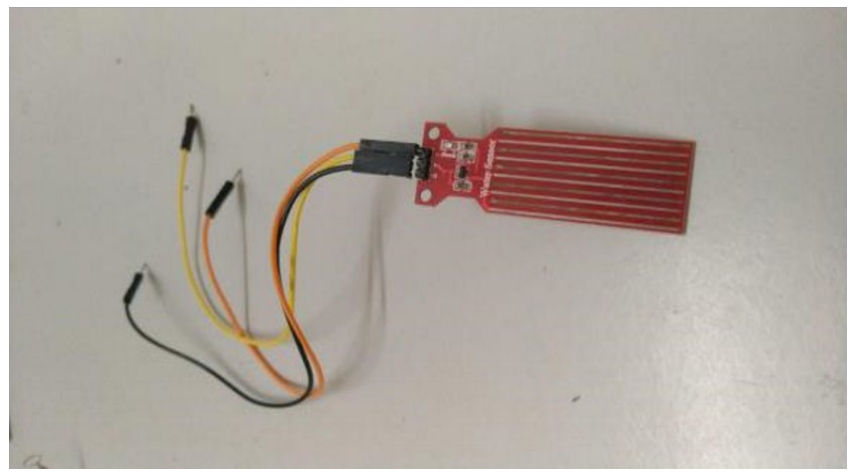

Fig 3: Water Level Sensor 
Relay:It is a hardware used instead of switch, which ON and OFF the motor, shown in below figure4. It is connected to a water level sensor where once the water level reaches to a certain rate it will tend to ON and OFF the motor automatically. It helps to control the water flow.

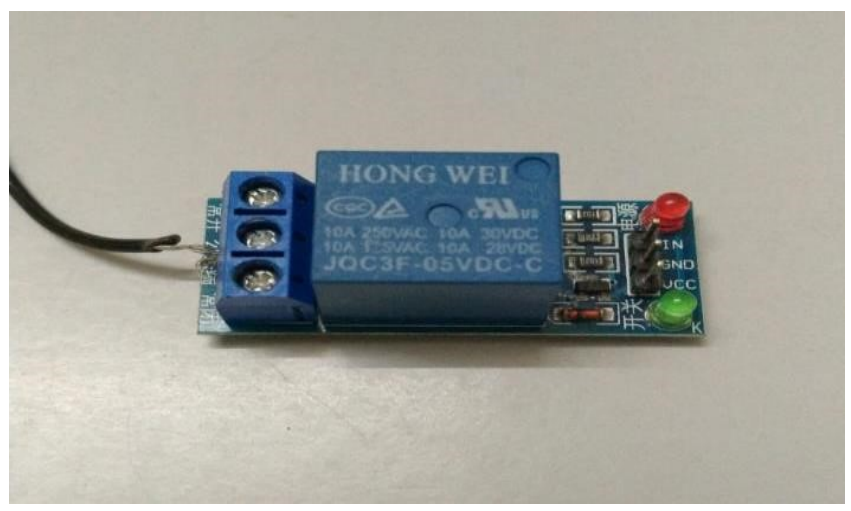

Fig 4: Relay used with Hardware

Wi-Fi Module(ESP8266 ): It is a highly activated chip, which is designed to provide the access or connectivity to the internet within a small package. It is limited only to a certain range of area. The status of the water level is passed to the owner through this. It can be used for the long distance from the user and controller.

LCD(Liquid Crystal Display):The LCD used is $16 * 2$ display, where the status or the updates are displayed. The connection of LCD is given to Arduino and Breadboard. It help to check the status of hardware for their parameter details, which is shown in figure5.

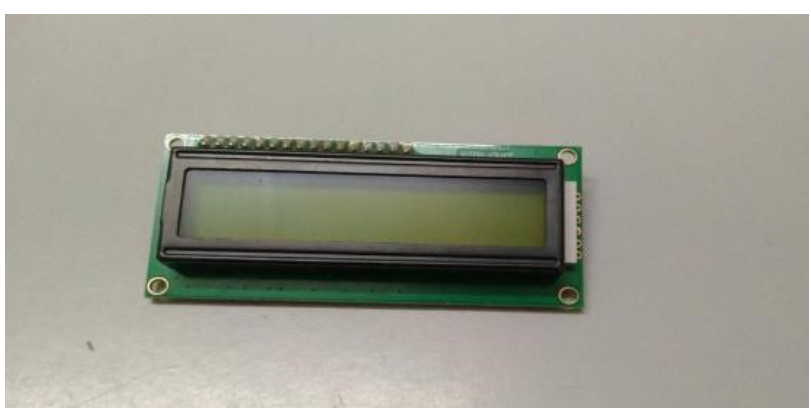

Fig 5: LCD display

3.2 Mathematical Model for AWMS:There are three factors which can effect the storage of water and lead to the wastage: Pipe leakage, Overflow and High flow in tap. In this work few assumptions are listed below: Let the size of the Water Tank: 1000 liter, pipe of the size of half inch diameter $(12.7 \mathrm{~mm})$.

Water flow rate $(\mathrm{Qw})$ has to be calculated in the case of pipe leakage $(0.5 \mathrm{inch})$ with diameter $\mathrm{d}$.

$$
\mathrm{Qw}=3600 * \pi * \mathrm{~V}(\mathrm{~d} / 2) 2
$$

Where: $V=$ Water velocity $(\mathrm{m} / \mathrm{s}), \mathrm{d}=$ Pipe inner diameter $(\mathrm{m}), \quad \mathrm{Qw}=$ Water flow $\operatorname{rate}(\mathrm{m} 3 / \mathrm{h})$

Velocity of water in a pipe from the tank: Velocity of water is directly proportional to the height of the water tank, which is assumed as 1 meter in this work.

$$
\operatorname{Vwp}=\operatorname{Cwv}(2 * g * h)^{1 / 2}
$$

Where:Cwv=Water velocity coefficient $(0.97), \mathrm{g}=$ gravity acceleration for water $(9.8 \mathrm{~m} / \mathrm{s} 2), \mathrm{h}=$ height of the water tank $(\mathrm{m})$.

$$
\mathrm{Vwp}=0.97 *(2 * 9.8 * 1) 1 / 2=4.2843
$$

Water Flow from the tank of 0.5 inch pipe(which is generally used in home):

$\mathrm{Vwf}=\mathrm{Cdf} * \mathrm{~F}(2 * \mathrm{~g} * \mathrm{~h})$ 
Where: Vwf=Water flow volume of pipe, $\mathrm{Cdf}=$ =ipe discharge coefficient, $\mathrm{F}=$ flow of water from pipe Flow area:

$$
\mathrm{F}=\pi \mathrm{r}^{2}
$$

$$
\begin{gathered}
\mathrm{F}=3.142 * 0.0127 * 0.0127=0.00056064 \mathrm{~m}^{2} \quad \\
\mathrm{Vwf}=0.6014 * 0.00056064 * 4.427=0.00134823 \mathrm{~m}^{3}
\end{gathered}
$$

One Liter $=1000 \mathrm{~cm}^{3}=0.001 \mathrm{~m}^{3} \mathrm{so} \quad 1000$ Liter water tank volume $=1000 * 0.001 \mathrm{~m}^{3}=1 \mathrm{~m}^{3}$

Time taken to empty the water tank of $1000 \mathrm{~L}=1 / 1.34823 * 10^{-3}=0.7416747 * 10^{3}$

From the above calculation, it shows that to empty any water tank with high force of water from half inch hole (pipe), it will take around 741.67 seconds or 12.36 minutes. So sensor will check the flow of water for a given threshold value, if its increases with that value than it will send the pop up message to user that there is a leakage in the pipe.

\section{Working of the System}

There are 4 levels in a water tank, and the levels are Empty, Low, Medium and High. A water level sensor RobodoSEN18 is placed inside the water tank. The yield of the sensors is sends to Web application using Arduino UNO and WIFI connectivity. The android web application gives the information about the status of the water level in the reservoir. When the water in the tank gets empty, it automatically TURN-ON the motor and this information will sends to the owner through a pop-up message. Similarly at the point when the water level gets high, the motor will TURN-OFF and the information will send as a message to the owner, shown in figure6. Overall flow of the system is shown in figure 7.

\subsection{Work flow of the AWMS:}

Step 1:If the water tank is empty the motor will automatically TURN ON through the switch(relay).

Step 2: The motor is TURNED ON, this data is send to the owner through pop-up message.

Step 3: As Step 2 all the levels of water in the tank will be send to the owner.

Step 4:WaterConservation()

\{if(level $>=$ mid \&\& level<=high) $\quad$ printf("the flow rate of water is controlled"); $\quad\}$

else \{ printf(“do not control”); \}\}

Step 5: Step 4 indicates the conservation of water level in the tank.

Step 6: Else the water level reaches to level high the switch automatically TURNS OFF and send the data to the owner.

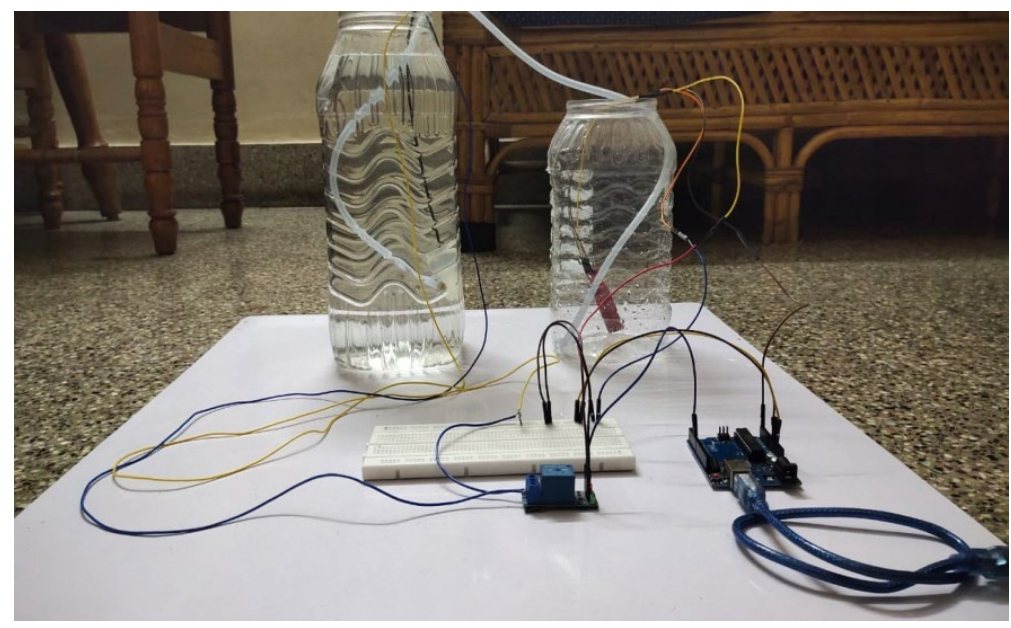

Fig 6: System Connection 


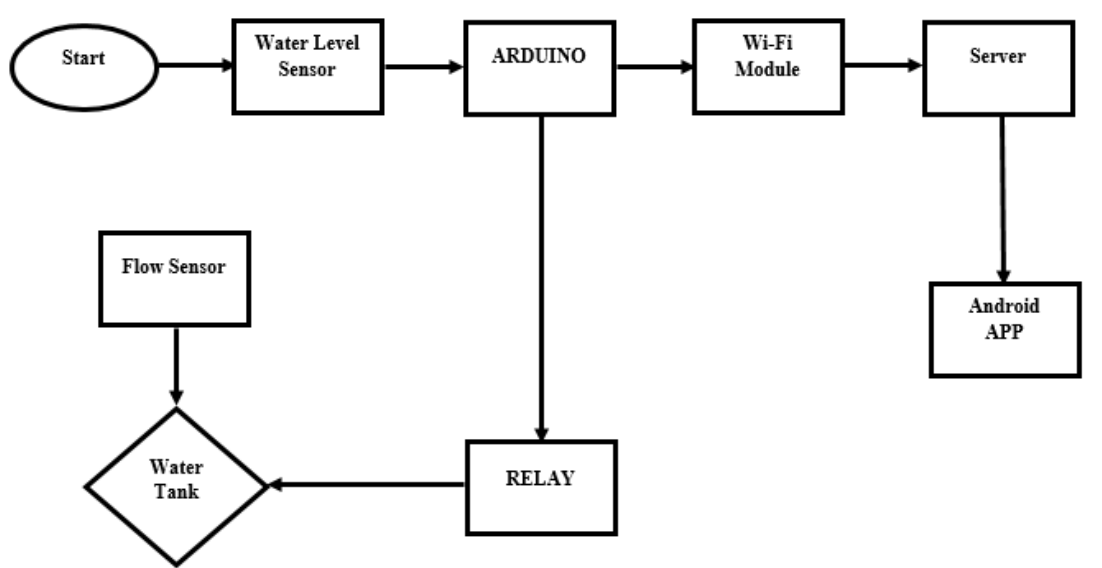

Fig 7: Overall Flow of work

\section{Advantages of the system}

It provides equitable water supply and reliability. It reduces the wastage of water. The water transmission and distribution is maintained. It improves the productivity of supply and utilization of water in urban communities and towns to improve liveability. The improvement in environmental condition of waterways is supported in community needs. It also maximizes the water withdrawal.

\section{Conclusion and Result}

Although the cities are getting urbanized, and the natural water resources are disappearing day by day in rural areas, so, it is very essential to conserve water in the present generation. Therefore the proposed system has many advantages in reducing the wastage of water which is compared in the figure 8 and 9 for housing areas, industries, agricultural fields, poultry farms,etc.

AWMS plays a pivotal role in reducing the wastage of water through the automated relay of motor for SWITCH ON and SWITCH OFF services with the sensors, notify the leakage in pipe if any and constant flow of water in tap. These all details users can check in their mobile phone through app. And also users will receive the pop up message in the case of leakage and get the status of water level in tanks as well as user can view the status through mobile phone app.

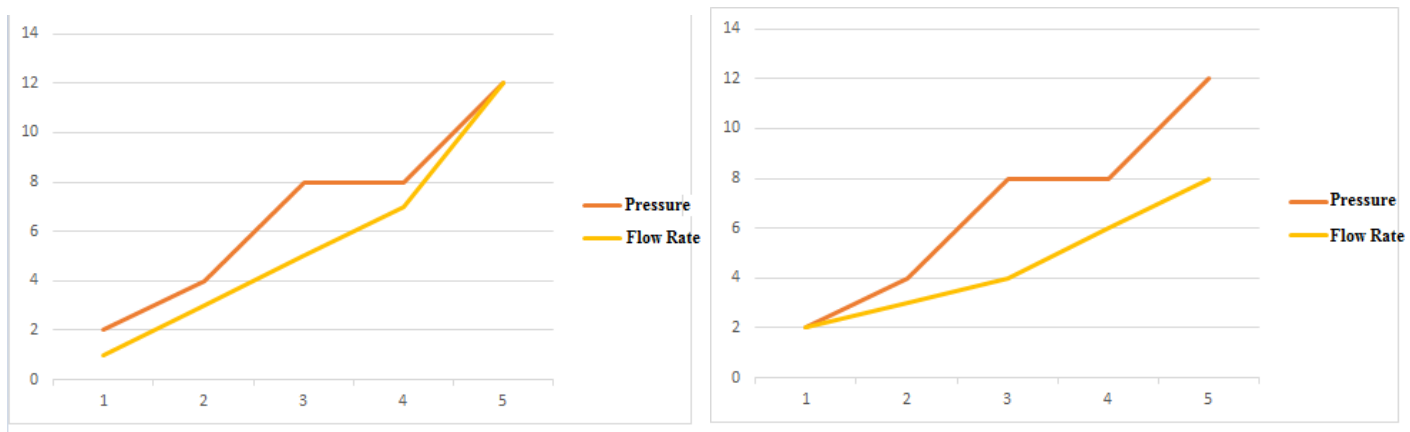

Fig 8: Existing System with pressure and flow rateFig 9:Present System with pressure and flow rate

\section{References}

1. Vinod Bharath et al.: Smart Water Management System in Cities , 2017 Internationl Conference on Big Data Analytics And Computational Intelligence(ICBDACI) IEEE.

2. Yogithapatil, Ramandeep Singh.: Smart water tank management system for residential colonies using Atmega 128A microcontrollers, 2014 International journal of scientific and engineering research IEEE, Volume 5, Issue 6.

3. Ayishasayed et al.: Smart and automatic water distribution control system, 2018 International research journal of engineering and technology (IRJET) IEEE, Volume 5, Issue 1.

4. S.Nalini Durga, et al.: Autonomous Water Tank Filling System Using IoT, 2018 IEEE, Volume 6, Issue 9. 
5. Chandra Rajurkar et al::IoT Based Water Management, 2017 International Conference on Nextgen Electronic Technologies IEEE.

6. BezaNegash et al.: Automatic Water Level Sensor and Controller System, 2016 IEEE.

7. Takshan Shetty et al.:Water level monitoring system, August 2018 International Research Journal of Engineering and technology (IRJET) IEEE, Volume 5, Issue 8.

8. F Ntambi, et al.: Design of Water Management System, 2015 Department of Electronic and Computer Engineering University of Pretoria IEEE.

9. Gowthamy J, et al.: Smart Water Monitoring System using IoT, 2018 International Research Journal of Engineering and technology (IRJET) IEEE, Volume 5, Issue 10.

10. Gaurav Gosavi, et al.: Smart Water flow Monitoring and Forecasting System, 2017 Recent Trends in Electronics Information and Communication Technology(RTEICT) IEEE.

11. Mr. Kuldip Singh, et al.: Real Time Based Water Supply Management System, 2014 GNITC IEEE.

12. Santosh Anand, Somnath Sinha.: 24X7 Lifeline Chip for soldiers ,procedia computer science, ISSN 1877-0509, 2020.

13. J.Daniel Francis Selvaraj, et al.: Automatic Wireless Water Management System(AWWMS) for Smart Vineyard Irrigation using IoT Technology, ISSN 0973-2667 Volume 13, Number 1 (2019), pp. 211-218.

14. Prof.Savita Lade, Prathamesh Vyas, et al.: Water Management System using IOT with WSN, 2018 International research journal of engineering and technology (IRJET) IEEE, Volume 5, Issue 03.

15. SanamPudasaini, et al.: Automatic Water Level Controller with Short Messaging Services(SMS) Notification, IJSRSET,2014, Volume 4, Issue 9.

16. Prof.Rucha Dixit, et al.: Water level and leakage detection system with its quality analysis based on sensor for home application, 2018 International research journal of engineering and technology (IRJET) IEEE, Volume 4, Issue 11.

17. Priya j, SailushaChekuri,:Water level monitoring system using IoT, 2017 International research journal of engineering and technology (IRJET) IEEE, Volume 4, Issue 12.

18. Monisha.S, et al.: Automatic Water Management System, IJSRSET 2016, Volume 2, Issue 2.

19. Pavankumar Naik, et al.: Arduino Based Automatic Irrigation system IoT, IJSRSET 2017, Volume 2, Issue 3.

20. PratikaBhondve, et al.: IoT Based Water Management System using Arduino, 2019 International research journal of engineering and technology (IRJET) IEEE, Volume 6, Issue 6. 